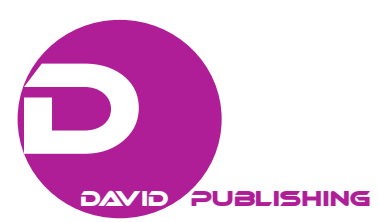

\title{
Analysis of Ejector Cooling Flow
}

\author{
Butovskyi Iegor, Kogut Volodimyr, Khmelniuk Mykhailo \\ Odessa National Academy of Food Technologies, Odessa, Ukraine
}

\begin{abstract}
Now there were different aspects of heat exchangers of ejectors who could work in broad range of speed regulation characteristics, and with the different cores and auxiliary substance flows. For affirming of estimated performances the bench had been project, allowing to change speed regulation characteristics of a main stream and to regulate metering characteristics of an auxiliary fluid flow. For affirming of estimated performances of a heat exchanger of an ejector the imitative bench and with a view of accident prevention had been project, cooled air and the prepare water actuation mediums. The bench had been positioned in an insulated cooled room. For putting off gauging the multifunctional measuring complex of TESTO 400, was taken the temperature a surrounding medium, and a water rate does regulate by us. The high speed photo cameras were applied to bracing of formation of drips. Strain-gauge balances apply to determination of mass of water on the shield. The air flow was shape, and moving in an ejector heat exchanger by means of the axial multiple-speed fan. The purpose of projection of a heat interchanger of an ejector is maintaining of airspeeds by means of the ventilator in the mixing chamber 10 to 80 meters per second. The temperature of given air was a stationary value, equal to $-20^{\circ} \mathrm{C}$. Temperature of injection water was varying from 4 to $20^{\circ} \mathrm{C}$.
\end{abstract}

Keywords: ejector heat exchanger, stain-gauge balances, insulated cooled room, cooling flow, hydrocarbons, working fluid

\section{Introduction}

This paper describes the application of inkjet devices in the refining industry. The authors emphasize on the new possibilities of application of jet devices with changing physical state of matter. An analysis of the heat exchanger ejector, is an experimental model of the flow behavior in the apparatus.

\section{Objects and Methods}

The calculation is based on the heat exchanger ejector laid the heat balance equation (during evaporation and condensation of the working substance from the main flow of hydrocarbons), the equation of momentum (quantity of motion).

The heat exchanger ejector simulation process is based on the heat balance and momentum equation describing the evaporation of working fluid and condensation of hydrocarbons main stream (Kogut \& Butovskyi, 2013).

Acknowledgements: I express my deep gratitude to my supervisor and mentor, Vladimir Kogut, also head of the Department of Refrigeration and Air Conditioning, which was carried out on the basis of this analysis.

Butovskyi Iegor, Ph.D. student, Odessa National Academy of Food Technologies, Odessa, Ukraine.

Kogut Volodymyr, associate professor, Odessa National Academy of Food Technologies, Odessa, Ukraine.

Khmelniuk Mykhailo, doctor of science (engineering), Odessa National Academy of Food Technologies, Odessa, Ukraine.

Correspondence concerning this article should be addressed to Butovskyi Iegor, ave Marshala Zhukova str. 79B, apt. 72, Odessa 65121, Ukraine. 


\section{Heat Exchanger Ejector Analysis}

Now, it is possible to represent a phenomenological (physical) model and explain the behavior of the stream in the apparatus. The air and vapor of low-boiling hydrocarbons of mixture enters to the heat exchange ejector at the high range, and the sub-cooled liquid is injected at a low speed and temperature. The most important phenomena in the process are the frontal resistance of droplets, evaporation, channel wall friction, and hydrocarbons condensation from the main stream (Kogut \& Khmelniuk, 2011).

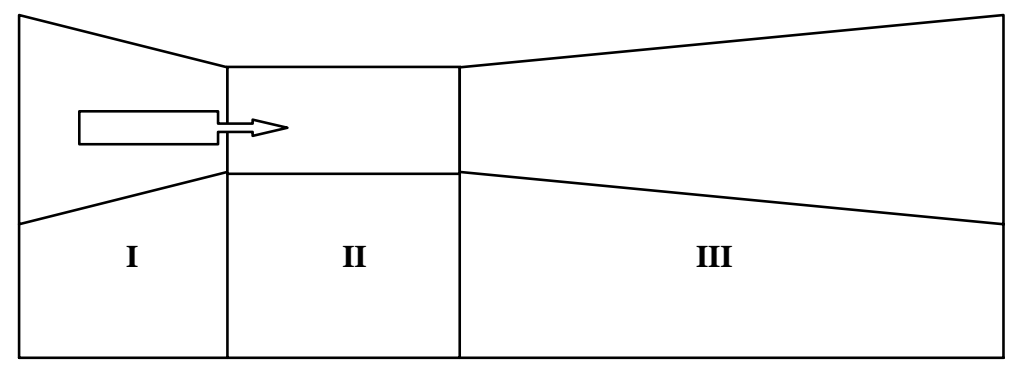

Figure 1. Distribution zones along the length of the heat exchanger ejector.

These described phenomena occur simultaneously (Figure 1):

Zone I. Air and vapors of low-boiling hydrocarbons gas stream acceleration, by narrowing of confusor (preparation for contact heat exchange);

Zone II. Active contact heat exchange between the main gas stream and the injected liquid (flash gas cooling);

Zone III. Stagnation of the flow and condensation of hydrocarbons from gas mixture (air is superheated and hydrocarbons are significantly subcooled).

\section{Design and Testing of Heat Exchanger Ejector}

A new method for condensation of hydrocarbon vapors in the stream represented in the work is the heat exchanger ejector (Kogut \& Khmelniuk, 2011). In order to establish dependencies condensation of hydrocarbons in the heat exchanger ejector from flow velocity and temperature of the working substance was an experimental study of the proposed unit on the designed stand by simulating real conditions of storage and overfilling of low-boiling fuels in Odessa at the company "Inzhmash Service Ltd".

Input parameters for the experiment are presented in Table 1 and Table 2.

Table 1

Content of Hydrocarbons in the Air Mixture Depending on the Temperature of Environment During the Overfilling From Tank Into the Tank (the Experimental Data)

\begin{tabular}{llll}
\hline Ambient temperature, ${ }^{\circ} \mathrm{C}$ & $0-20$ & $20-30$ & $30-45$ \\
\hline Gasolines conventional brands & $5-7 \%$ & $7-12 \%$ & $15-20 \%$ \\
Diesel fuel (summer) & $3-4 \%$ & $5-6 \%$ & $8-10 \%$ \\
Bioethanol fuel & $4-5 \%$ & $6-10 \%$ & $12-22 \%$ \\
\hline
\end{tabular}

Table 2

Temperature of the Working Substance Injected Into the Main Stream of Air and Hydrocarbons Mixture

\begin{tabular}{llll}
\hline Working substance & Refrigerated hydrocarbons & Carbon dioxide & The inert gas is nitrogen, as a liquid \\
\hline Injection temperature & $5^{\circ} \mathrm{C}$ to $10^{\circ} \mathrm{C}$ & $-80^{\circ} \mathrm{C}$ to $-75^{\circ} \mathrm{C}$ & $-195^{\circ} \mathrm{C}$ to $-180{ }^{\circ} \mathrm{C}$ \\
\hline
\end{tabular}


The main objective of the experiment is to confirm the full condensation of hydrocarbons. The experimental stand (Patent of Ukraine, 2014a; 2014b) consists of three tanks, connecting $100 \mathrm{~mm}$ pipelines, heat exchanger ejector, two strain-gauge balances, liquid hydrocarbons pump (various grades of gasoline, bioethanol and diesel fuel) and an explosion-proof fan (Kogut \& Khmelniuk, 2011a; 2011b) (Figure 2).

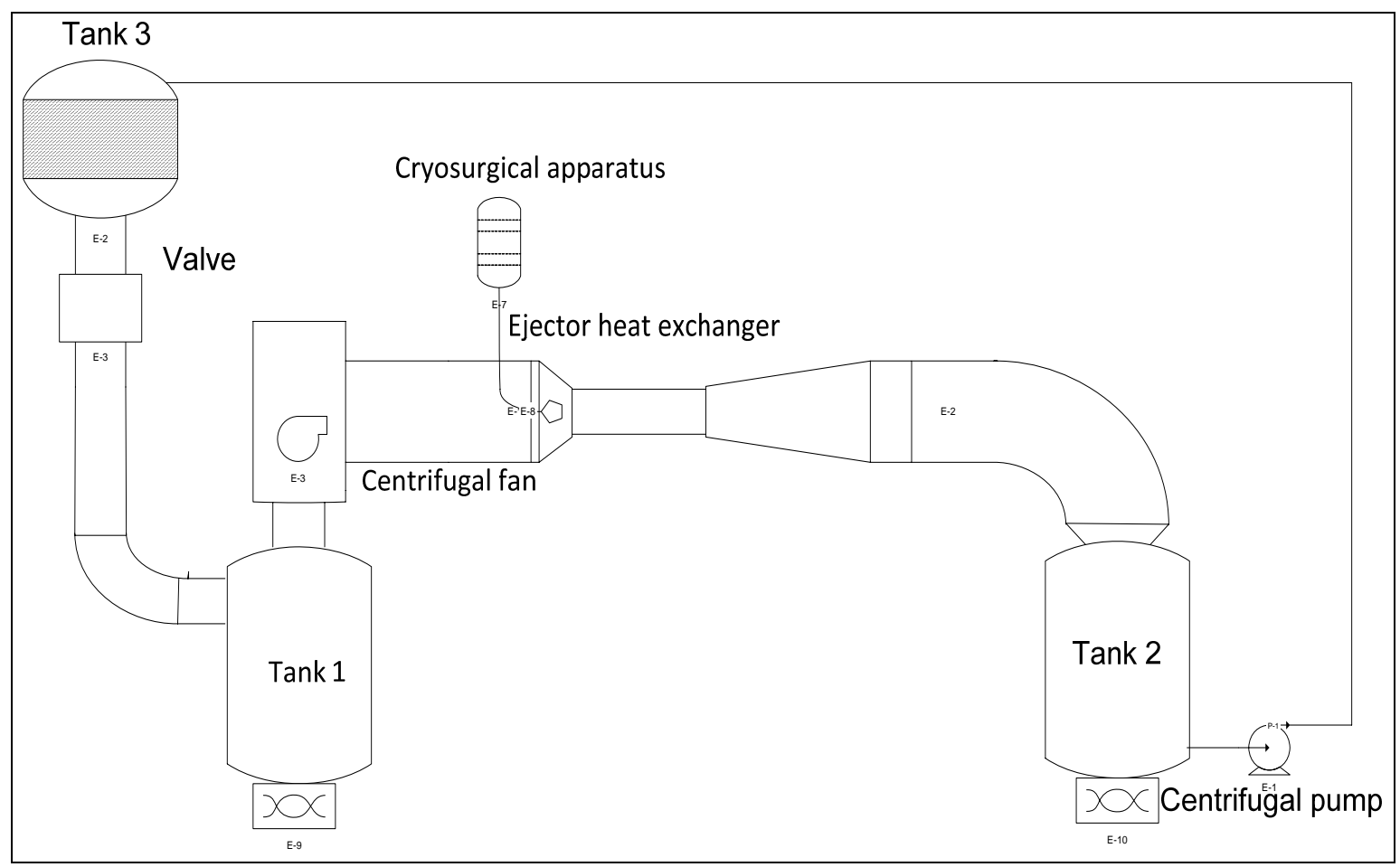

Figure 2. Experimental setup refrigeration system in the stream of hydrocarbon condensation.

The hypothesis of the heat exchanger ejector application for hydrocarbon condensation is checked out using the following methods (Kogut \& Khmelniuk, 2011a):

(1) Liquid nitrogen is ejected into the accelerated stream of vapor of hydrocarbons with the temperature $-193{ }^{\circ} \mathrm{C}$;

(2) The vapor nitrogen with temperature $-70{ }^{\circ} \mathrm{C}$ ejected a vapor hydrocarbons flow with speed of $25 \mathrm{~m} / \mathrm{s}$ before the heat exchanger ejector;

(3) Except nitrogen, the carbon dioxide is used as a working fluid in the open-cycle mode.

The experiment is carried out at the carbon dioxide cycle parameters. During the experiment the hydrocarbons are fully condensated and the amount of working fluid what is necessary for full condensation is determined. The rate of flow in a heat exchanger ejector is experimentally selected and matched to a Mach number $\mathrm{M}=0.3$. Initial fuel temperature matched to $25-45^{\circ} \mathrm{C}$.

Figure 3 shows the quantity change of working substance curves depending on the temperature in the camera of condensation of a heat exchanger ejector in which the full fuel condensation is made.

Also by means of a mathematical MathCad 14 package and a program platform for computer model operation of physical tasks COMSOL Multiphysics the comparative analysis of amount of fluid nitrogen for cooling of air mix with fluid hydrocarbons was carried out that is shown on Figures 5 and 6 . Also capacity rating of system when using several (to the $3 \mathrm{rd}$ ) nozzles in an ejector heat exchanger was made. 
Efficiency of the ULF system with the ejector heat exchanger can be regulated by portion method, including in turn several nozzles that are shown in calculations.

$\mathrm{G}_{\text {nitrogen }}=0.17 \mathrm{~kg} /$ hour - Efficiency of one nozzle

$\mathrm{G}_{\text {nitrogen }}=0.34 \mathrm{~kg} /$ hour - Efficiency of two nozzle

$\mathrm{G}_{\text {nitrogen }}=0.51 \mathrm{~kg} /$ hour - Efficiency of three nozzle

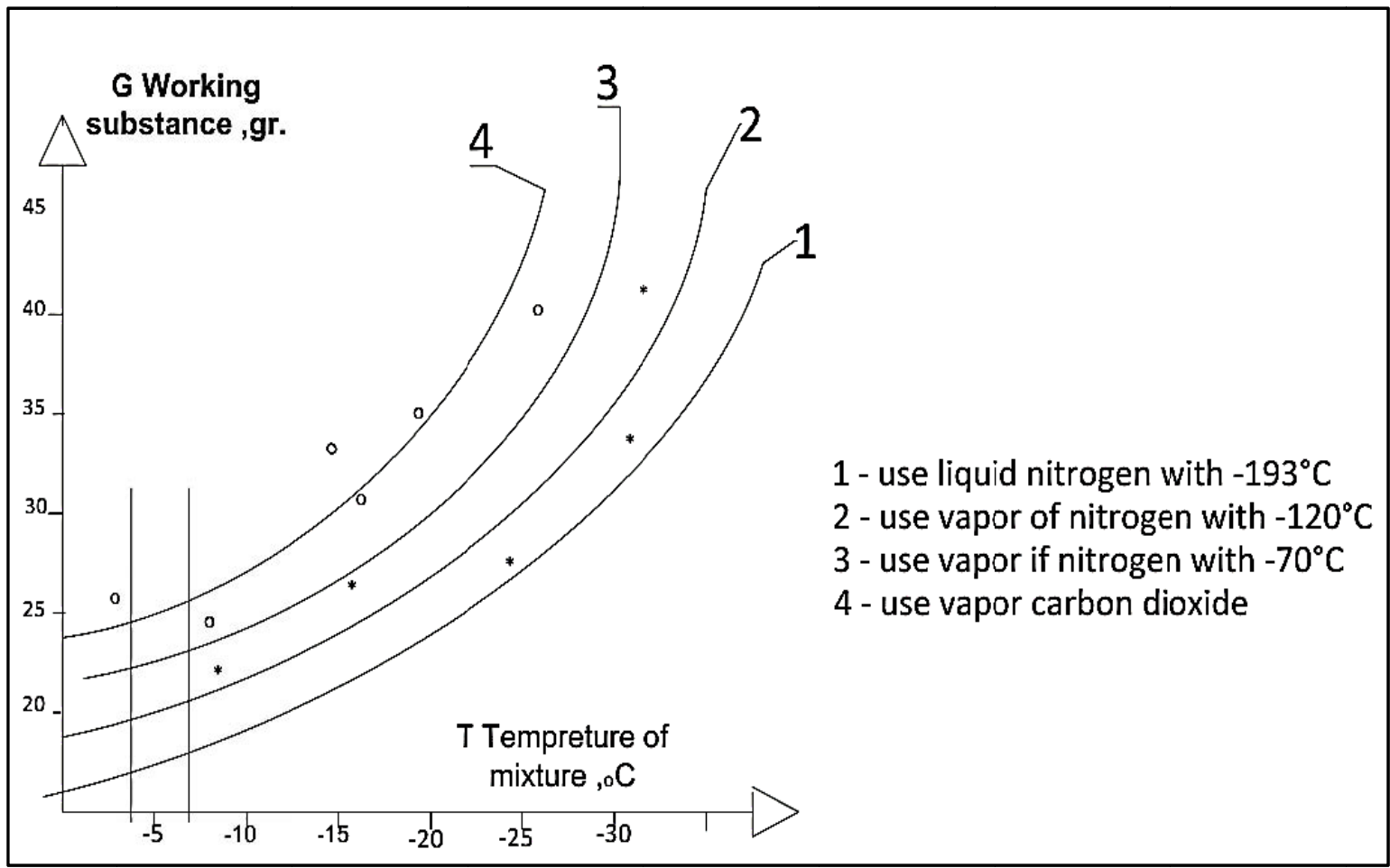

Figure 3. Dependence of amount change of the working substance against the temperature in a heat exchanger ejector.

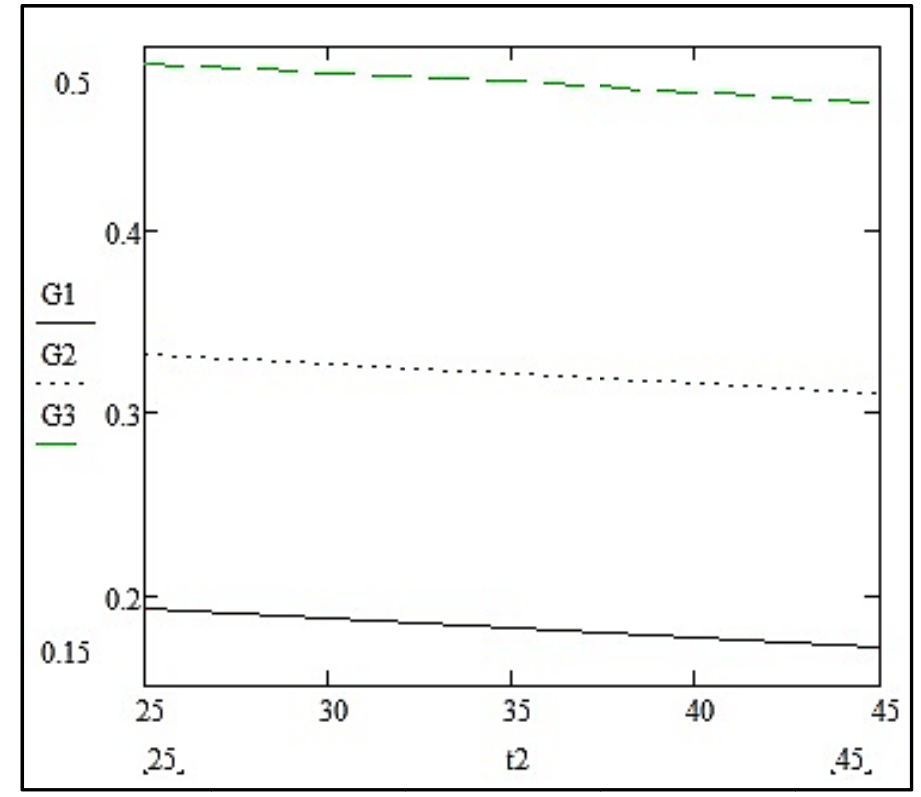

Figure 4. The drawing of a consumption of fluid nitrogen for cooling of fluid hydrocarbons. 


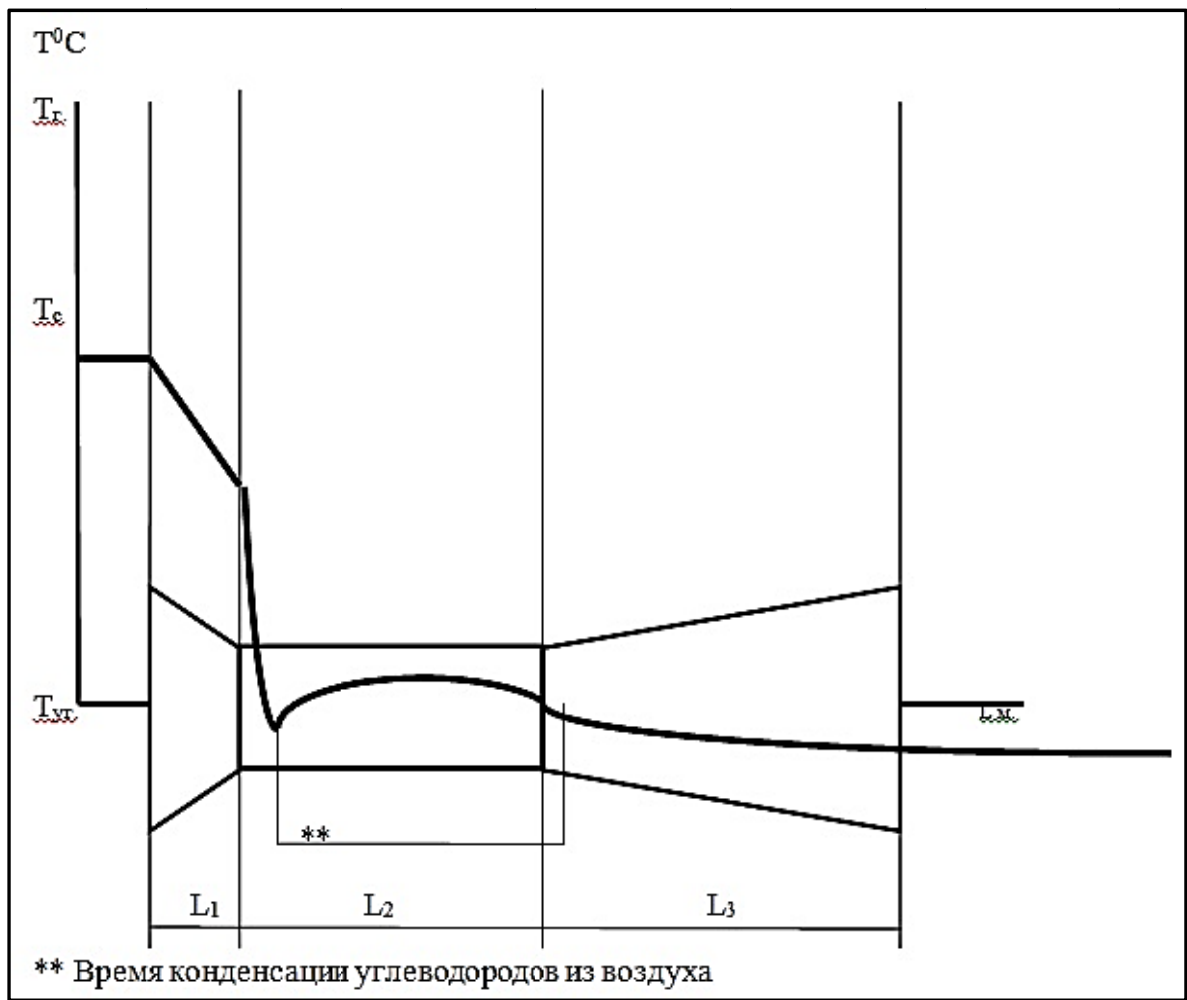

Figure 5. The drawing of change of temperature of air mix and hydrocarbons on driving in an ejector the heat exchanger. Note. $* *$ time of condensation of hydrocarbons from air.

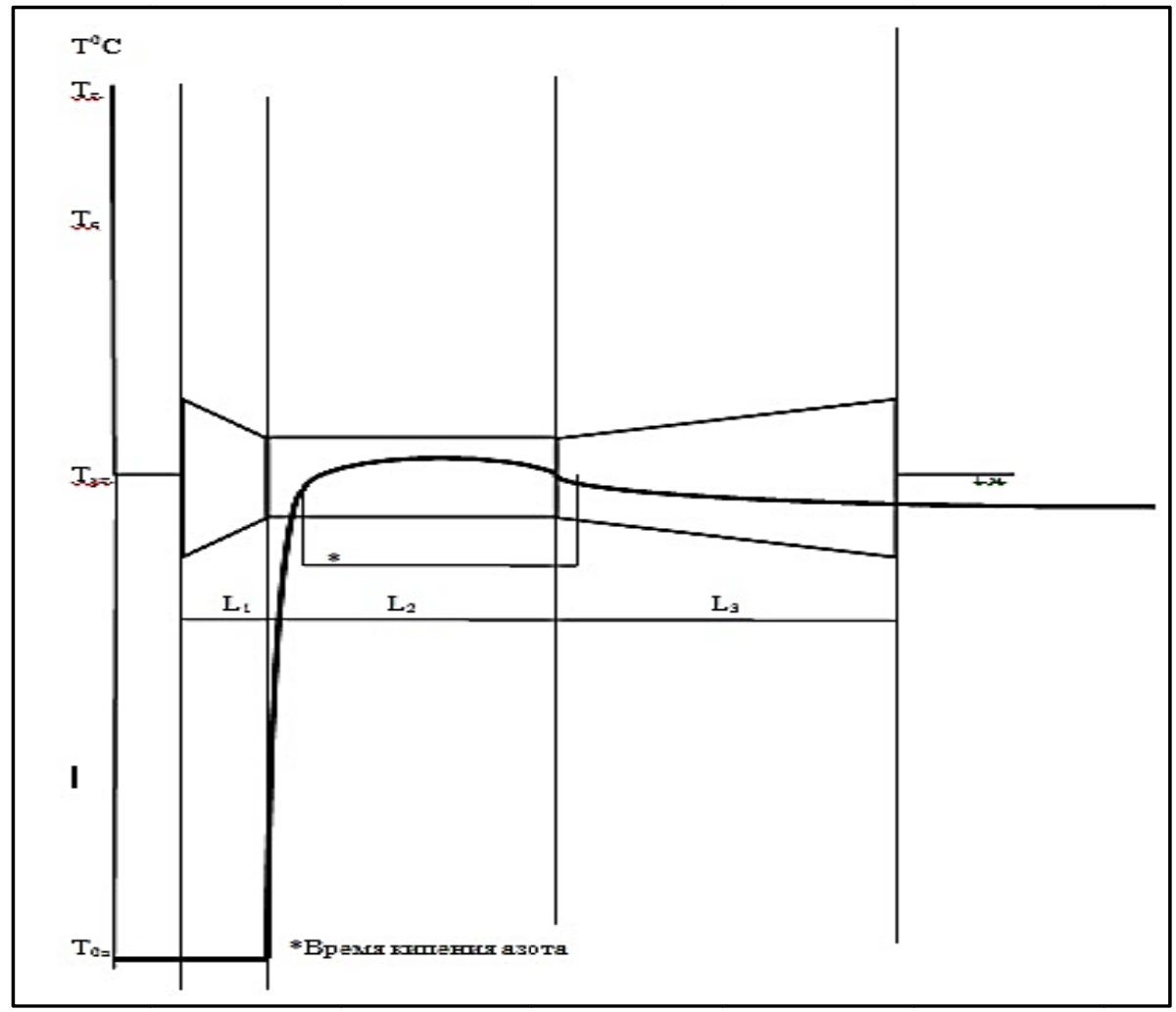

Figure 6. The drawing of change of temperature of nitrogen on driving in an ejector the heat exchanger. Note. * nitrogen boiling time. 


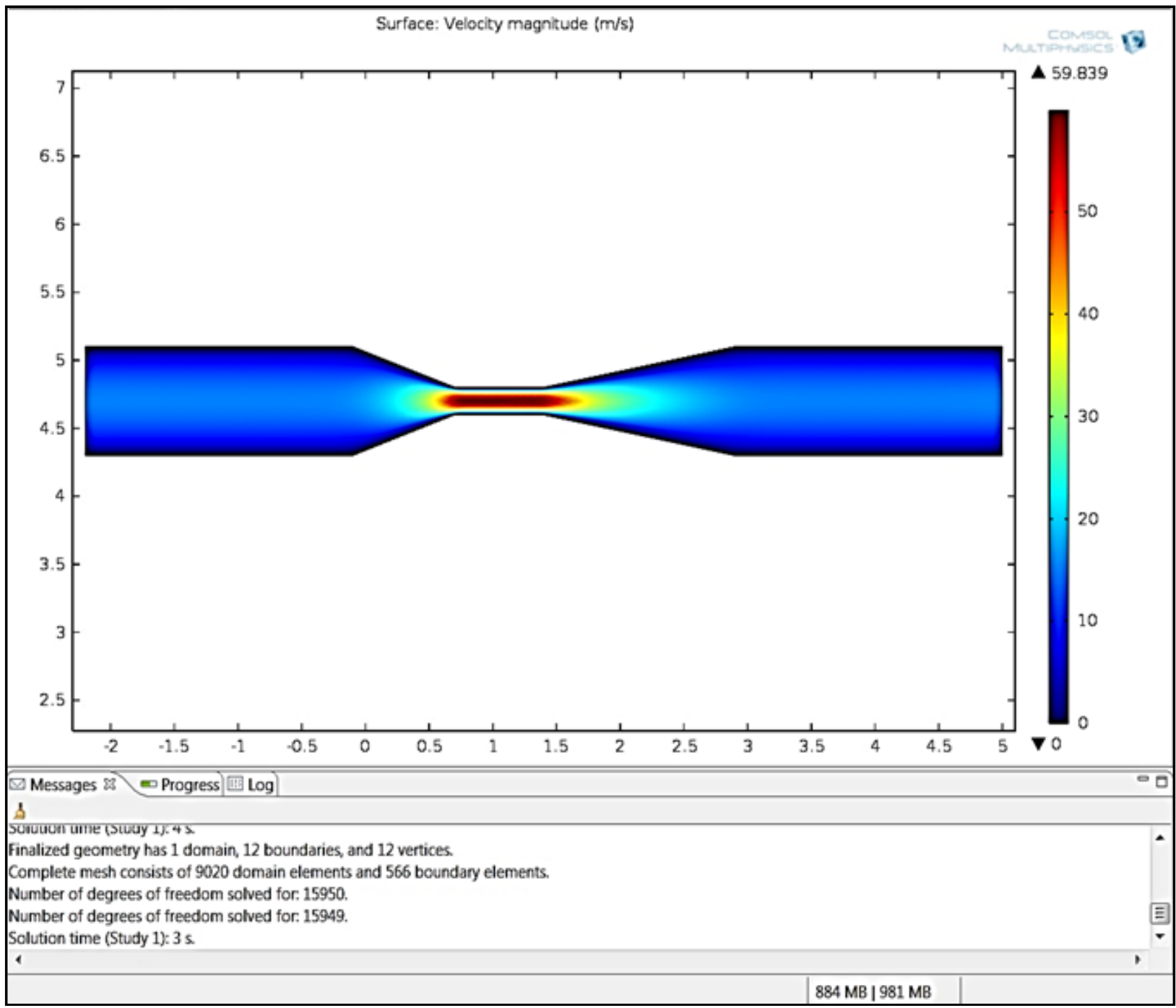

Figure 7. The drawing of speed of streams in the ejector heat exchanger.

\section{Results}

The expense working substance, namely the nitrogen given to the ejector heat exchanger is equal to 1.6 $\mathrm{m}^{3} / \mathrm{h}$. Respectively, the peak discharge of a gas phase in the pilot unit makes $8 \mathrm{~m} / \mathrm{h}$.

The coefficient of correlation is 0.93 . The main divergence of the experimental and theoretical sizes occurs in the field close to zero. This area at practical application is not of great importance since use of ejector system of catching of light distillates is expedient at extent of catching more than $70 \%$. Based on the selection made of the above-named condition, the average square error of theoretical calculation of size of extent of catching is $12.6 \%$.

Results of experiment demonstrated that for spread brands of gasoline the condensing temperature is in the range from -7 to $-4{ }^{\circ} \mathrm{C}$, in dependence of seasons and brands of gasoline.

According to thermophilically characteristics, condensing temperature of low-boiling hydrocarbon fractions is in the range of $15-25^{\circ} \mathrm{C}$. It is experimentally determined that the rapid fuel condensates which fall from air occur when the liquid sub cooling is in the range of $15-20^{\circ} \mathrm{C}$ and the air is extremely superheated. 
Application of the heat exchanger ejector accelerates and improves the heat exchange between the working substance and a mixture of air and hydrocarbons.

\section{Conclusion}

The $\mathrm{R} \& \mathrm{D}$ work included the problem analysis in operation practice and design of liquid hydrocarbons conservation systems during the transportation and transferring it from tank to tank. The application of liquid nitrogen for condensation hydrocarbons from the air is profitable at flow rate of 20-40 grams per 100 grams of condensed fuel. The experimental results confirmed the relevance of nitrogen and carbon dioxide application for cooling the mixture of air and hydrocarbons of various brands of gasoline, bioethanol, and diesel fuel for the hydrocarbons separation.

Application of heat exchanger ejector provides ecological and fire-safety hydrocarbons emission into the atmosphere. The relevant factor is the decreasing of bioethanol fuel components evaporation to ensure the safety of hydrocarbons and fuel qualitative indexes.

\section{References}

Kogut, V., \& Khmelniuk, M. (2011a). Questions of safety in transportation and storage of petroleum products. Abstracts of papers presented on Second International Scientific Conference "Innovations in Shipbuilding and Ocean Engineering", Nikolaev, October 5-7, 2011.

Kogut, V., \& Khmelniuk, M. (2011b). Experimental study on condensation heat exchanger ejector hydrocarbon stream. Abstracts of papers presented on 7th International Exchange of Scientific and Technical Conference "Modern Problems of Refrigeration Engineering Technology", Odessa, September 14-16, 2011.

Kogut, V., \& Butovskyi, I., \& Nosenko N. (2013). Refrigeration system for condensation of hydrocarbons in the stream. Refrigeration Engineering and Technology - Odessa, \#5.

Patent of Ukraine. (2014a). Method of hydrocarbon vapor condensation. No. 92548, 26.08.2014.

Patent of Ukraine. (2014b). Unit for condensation of hydrocarbon vapors in the stream. No. 92555, 26.08.2014. 